\title{
The Occurrence of Polythionates as Intermediates in the Metabolism of Thiosulphate by the Thiobacilli
}

\author{
G. L. JONES AND F. C. HAPPOLD \\ Department of Biochemistry, The University of Leeds
}

(Received 1 May 1961)

\section{SUMMARY}

Further evidence for the inclusion of polythionates in the pathway of thiosulphate oxidation by members of the genus Thiobacillus is presented. Manometric experiments showed tetrathionate oxidation to be a stage in thiosulphate oxidation by suspensions of $T$. thioparus and T.thiocyanoxidans. Thiobacillus thioparus accumulated a sufficient concentration of polythionate in the medium to allow chromatograms to be prepared, and the type of polythionate accumulated was influenced by the ratio between the sodium and potassium ions in the medium. The restriction of the oxidation of tetrathionate at the lower concentrations of $\mathrm{K}^{+}$may be due to a restriction in the entry of phosphate into the cell during growth; this is discussed.

\section{INTRODUCTION}

The first report of polythionate accumulation by a Thiobacillus sp. growing in a thiosulphate medium was made by Nathansohn (1902) when he described the accumulation of an incompletely oxidized sulphur compound which did not react with iodine, but which was oxidized to sulphate by bromine. Since that time there have been several attempts to show the accumulation of polythionates by these organisms. Starkey (1935) was unable to detect the formation of polythionates by pure cultures of $T$. thioparus and T. novellus. He showed the formation of tetrathionate in cultures of $\boldsymbol{T}$. trautweinii, which he considered was a heterotrophic organism and which has since been reported to be facultatively autotrophic (Parker \& Prisk, 1953). Skarzynski \& Szczepkowski (1959), by using a chromatographic method, were unable to detect the presence of polythionates in cultures of $T$. thioparus; they concluded that polythionates were not concerned in thiosulphate oxidation. The manometric experiments of Vishniac (1952) suggested that tetrathionate and trithionate were intermediates, whilst Trudinger (1959) showed the incorporation of radioactive ${ }^{35} \mathrm{~S}$ into tetrathionate and trithionate, and subsequently into a compound which he was unable to identify. Parker \& Prisk (1953) showed the formation of tetrathionate by some Thiobacillus spp., but not by $T$. thioparus, and Pratt (1958) showed the formation of polythionate by the strains of $T$. thioparus and $T$.thiocyanoxidans used in this work.

Organisms

\section{METHODS}

Thiobacillus thiocyanoxidans. A strain derived from a single rod obtained from a crude culture oxidising thiocyanate.

Thiobacillus thioparus. The original culture was obtained from the National 
Collection of Industrial Bacteria-NCIB 8370-described as 'Starkey's original non-motile strain'. This culture was purified by the isolation of a single colony on a thiosulphate agar plate.

Both these organisms have been maintained on thiosulphate agar slopes with weekly subculturing.

\section{Thiosulphate medium}

A solution containing: $10 \cdot 0$ g. $\mathrm{Na}_{2} \mathrm{~S}_{2} \mathrm{O}_{3} .5 \mathrm{H}_{2} \mathrm{O} ; 3.5 \mathrm{~g} . \mathrm{KH}_{2} \mathrm{PO}_{4} ; 1 \cdot 4 \mathrm{~g}$. $\mathrm{KOH}$; $0.1 \mathrm{~g} . \mathrm{NH}_{4} \mathrm{Cl}$; in 1 l. glass distilled water was autoclaved at $120^{\circ}$ for $15 \mathrm{~min}$., and after cooling, $10 \mathrm{ml}$. each of the sterile salt solutions $\mathbf{B}$ and $\mathbf{C}$ were added. Salt solution $\mathrm{B}$ contained $1.0 \mathrm{~g} . \mathrm{MgSO}_{4} \cdot 7 \mathrm{H}_{2} \mathrm{O} ; 0.2 \mathrm{~g} . \mathrm{MnSO}_{4} \cdot 4 \mathrm{H}_{2} \mathrm{O} ; 0.2 \mathrm{~g} . \mathrm{FeCl}_{3} ; 3 \mathrm{ml}$. concentrated hydrochloric acid; glass distilled water to $100 \mathrm{ml}$. Salt solution $\mathrm{C}$ was a solution $(1 \%, w / v)$ of calcium chloride in glass distilled water. Both salt solutions were sterilized by autoclaving at $120^{\circ}$ for $15 \mathrm{~min}$. The complete medium was at pH 7. Solid media were prepared by adding $4 \%(\mathrm{w} / \mathrm{v})$ washed agar to thiosulphate medium prepared at twice the concentration shown above to give a final agar concentration of $2 \%(w / v)$.

\section{Suspensions of organism}

The organisms were grown in $2 \times 5$ l. batches aerated with air containing $5 \%$ $(\mathrm{w} / \mathrm{v})$ carbon dioxide at $30^{\circ}-\mathbf{3 2}{ }^{\circ}$ for 3-4 days. Harvesting was carried out with $\mathrm{a}$ de Laval centrifugal separator and a refrigerated M.S.E. centrifuge. All the equipment coming into contact with the organisms during harvesting was sterilized before use. Ten 1 . of thiosulphate medium produced about $1.0 \mathrm{~g}$. wet wt. organism which was suspended in $20 \mathrm{mI}$. of $\mathrm{M} / 15$ phosphate buffer ( $\mathrm{pH} \mathrm{7.0)}$ ) made from $\mathrm{Na}_{2} \mathrm{HPO}_{4}$ and $\mathrm{KH}_{2} \mathrm{PO}_{4}$.

\section{Manometry}

Manometric experiments were carried out in a conventional Warburg apparatus under aerobic conditions at $30^{\circ}$. Carbon dioxide was absorbed with filter paper soaked in $0.2 \mathrm{ml} .20 \%(\mathrm{w} / \mathrm{v}) \mathrm{KOH}$ solution in the centre well. Substrate $(0.5 \mathrm{ml}$. $\mathrm{M} / 50$ ) was put in the side arm, $1.0 \mathrm{ml}$. of cell suspension in the main compartment with $\mathrm{M} / 15$ phosphate buffer ( $\mathrm{pH} 7 \cdot 0$ ), to bring the total volume of the flask contents to $3.0 \mathrm{ml}$. The flasks and manometers were equilibrated in the bath for $15 \mathrm{~min}$. before the reaction was started.

\section{Estimation of polythionate}

The method used was that described by Starkey (1934) which depends on the conversion of polythionates to thiosulphate and sulphite when heated with $\mathrm{KOH}$.

\section{Chromatography}

Identification of the accumulated polythionates was attempted by ascending chromatography, with the solvent isopropanol + acetone + water + potassium acetate $(50+20+30+2$ g.) described by Pollard, McOmie \& Jones (1955). Portions (10 ml.) of culture filtrate was freeze-dried, taken up in $0.5 \mathrm{ml}$. distilled water, and spotted on acid-washed Whatman No. 1 chromatography paper. After running for $5 \mathrm{hr}$. 
the chromatograms were dried, sprayed with $0.5 \mathrm{~N}$-silver nitrate, and excess silver removed by successive washings with water, $50 \%(\mathrm{w} / \mathrm{v})$ sodium thiosulphate solution, and water. The markers used for chromatography were sodium thiosulphate (Analar) and the potassium salts of tetrathionate and trithionate prepared by the methods described by Stamm, Goehring \& Feldmann (1942).

\section{RESULTS}

\section{Manometric experiments}

Manometric experiments on the oxidation of thiosulphate showed similar results for suspensions of both organisms. The change in slope of the thiosulphate oxidation curve reported by Vishniac (1952) was observed, although in our experiments this change occurred after an oxygen consumption in excess of the $56 \mu$ l. reported by

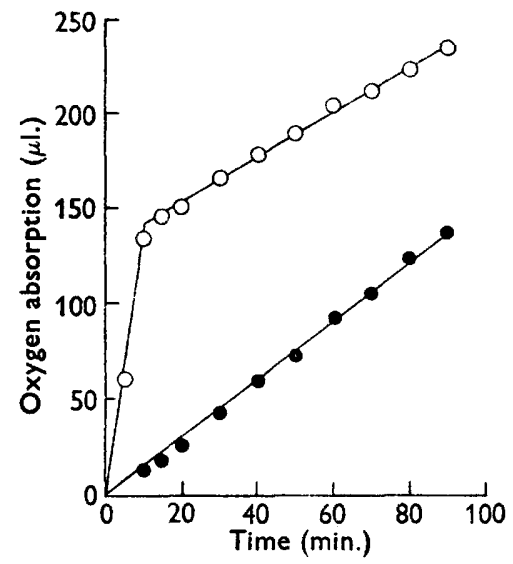

$a$

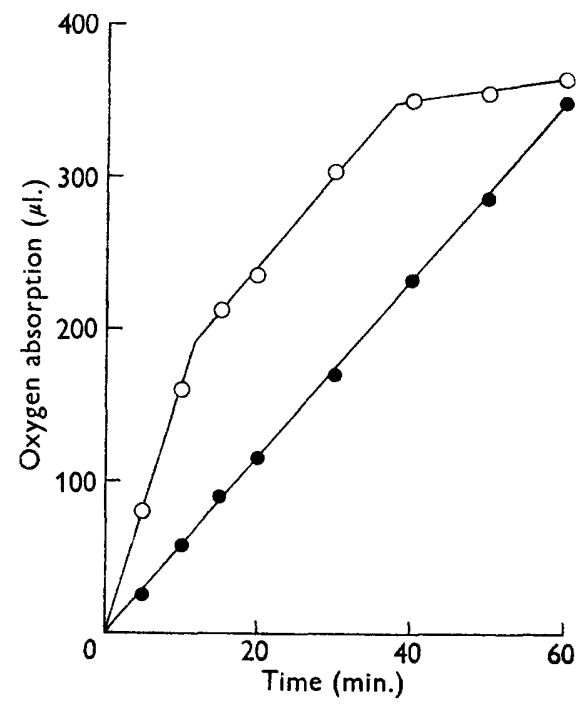

$\boldsymbol{b}$

Fig.1. (a) Oxidation of thiosulphate $\bigcirc$, and tetrathionate $\bullet$, by suspensions of Thiobacillus thioparus. (b) Oxidation of thiosulphate $O$, and tetrathionate $\bullet$, by cell suspensions of Thiobacillus thiocyanoxidans.

Vishniac. Figures. $1 a$ and $b$ shows the rates of thiosulphate and tetrathionate oxidation by Thiobacillus thioparus and $T$. thiocyanoxidans. We endeavoured to obtain evidence of the presence of tetrathionate at the time when the change in slope occurred. To stop the reaction, the reaction mixture from the flasks was tipped into ethanol, the organisms centrifuged down and the supernatant fluid freeze-dried. Chromatograms showed no trace of polythionate.

\section{Accumulation of polythionates}

In the standard medium cultures of Thiobacillus thioparus accumulated considerable amounts of polythionate in the medium during growth. The chromatogram obtained from cultures of $T$. thioparus grown at $32^{\circ}$ in static culture for $67 \mathrm{hr}$. showed a spot which corresponded to the trithionate marker. With further incubation 
another spot running in advance of the tetrathionate marker appeared which we think may be pentathionate. Our attempts to prepare a pentathionate standard with which to make a direct comparison were unsuccessful.

In their review on the thiobacilli, Vishniac \& Santer (1957) gave details of a requirement for either phosphate or arsenate to allow complete oxidation of thiosulphate to sulphate by suspensions of Thiobacillus thioparus. Experiments were therefore carried out with media containing higher concentrations of sodium potassium phosphate buffer than usual in an attempt to suppress the accumulation of polythionate in cultures of $\boldsymbol{T}$. thioparus. The results of such an experiment are shown in Table 1. The phosphate concentrations used were of the same order as those described by Vishniac \& Santer (1957) for their manometric experiments.

Table 1. The effect of phosphate concentrations upon the utilization of thiosulphate and the accumulation of polythionate $\left(\mathrm{S}_{n} \mathrm{O}_{6}\right)$ by Thiobacillus thioparus

Cultures were grown in $250 \mathrm{ml}$. conical flasks containing $50 \mathrm{ml}$. of medium. Each culture was inoculated with $0.5 \mathrm{ml}$. of an aseptically filtered 4-day thiosulphate grown culture.

\begin{tabular}{|c|c|c|c|c|c|c|c|c|c|c|c|c|c|c|c|}
\hline \multirow{3}{*}{$\begin{array}{l}\text { Time } \\
\text { (hr.) }\end{array}$} & \multicolumn{15}{|c|}{ Phosphate concentration } \\
\hline & \multicolumn{3}{|c|}{$\mathrm{M} / \mathbf{1 0}$} & \multicolumn{3}{|c|}{$\mathbf{M} / \mathbf{2 0}$} & \multicolumn{3}{|c|}{$\mathbf{M} / \mathbf{3 0}$} & \multicolumn{3}{|c|}{$\mathrm{M} / \mathbf{1 0 0}$} & \multicolumn{3}{|c|}{$\mathrm{M} / \mathbf{2 5 0}$} \\
\hline & $\mathrm{S}_{2} \mathrm{O}_{3}$ & $\mathrm{~S}_{n} \mathrm{O}_{6}$ & $\mathrm{pH}$ & $\mathrm{S}_{2} \mathrm{O}_{3}$ & $\mathrm{~S}_{n} \mathrm{O}_{6}$ & $\mathrm{pH}$ & $\mathrm{S}_{2} \mathrm{O}_{3}$ & $\mathbf{S}_{n} \mathrm{O}_{6}$ & pH & $\mathrm{S}_{2} \mathrm{O}_{3}$ & $\mathrm{~S}_{n} \mathrm{O}_{6}$ & $\mathrm{pH}$ & $\mathrm{S}_{2} \mathrm{O}_{3}$ & $\mathrm{~S}_{n} \mathrm{O}_{6}$ & $\mathrm{pH}$ \\
\hline 0 & 196 & 2 & 6.78 & 201 & 0 & $6 \cdot 78$ & 205 & 1 & 6.78 & 208 & 0 & $6 \cdot 46$ & 198 & 1 & 5.97 \\
\hline 23 & 196 & 6 & $6 \cdot 85$ & 192 & 8 & $6 \cdot 84$ & 195 & $\mathbf{9}$ & $6 \cdot 78$ & 196 & 10 & $6 \cdot 59$ & 190 & 11 & 6.2 \\
\hline 47 & 168 & 4 & $6 \cdot 68$ & 162 & 31 & $6 \cdot 74$ & 175 & 22 & $6 \cdot 71$ & 167 & 37 & $6 \cdot 78$ & 137 & 37 & $6 \cdot 55$ \\
\hline 71 & 143 & $\mathbf{3}$ & $6 \cdot 65$ & 153 & 27 & $6 \cdot 71$ & 129 & 64 & $6 \cdot 83$ & 130 & 75 & $7 \cdot 00$ & 78 & 59 & $6 \cdot 39$ \\
\hline 95 & 126 & 2 & $6 \cdot 63$ & 117 & 53 & 6.78 & 86 & 102 & $6 \cdot 89$ & 86 & 90 & $7 \cdot 27$ & 2 & 77 & $5 \cdot 86$ \\
\hline 115 & 75 & 2 & 6.59 & 60 & 100 & 6.75 & 47 & 119 & $6 \cdot 76$ & 53 & 124 & $7 \cdot 36$ & 0 & 75 & 4.07 \\
\hline $139 \cdot 5$ & 79 & 4.5 & $6 \cdot 6$ & 23 & 109 & $6 \cdot 72$ & 18 & 128 & $6 \cdot 74$ & 18 & 162 & $7 \cdot 32$ & 0 & 83 & $4 \cdot 23$ \\
\hline
\end{tabular}

Polythionate accumulation was greatly decreased at the highest concentration but in this medium the thiosulphate was not completely utilized. Examination of the chromatograms from these cultures again showed two spots other than that for thiosulphate. The unknown component running in advance of tetrathionate again appeared, but in place of trithionate a spot corresponding to the tetrathionate marker was observed.

The effect of varying the ratio between sodium and potassium ions in the medium was examined. The method used for increasing the phosphate concentration of the medium in the previous experiment increased the ratio between the sodium and potassium ions in the medium. Thus the medium described in the methods section has a ratio of $0.93 \mathrm{~g}$. ion sodium: $1 \mathrm{~g}$. ion potassium, whereas in the experimental cultures this ratio varied betwcen 4.2:1 for $\mathrm{M} / 10$ phosphate and $21 \cdot 4: 1$ for $\mathrm{M} / 250$ phosphate. It seemed possible that this increased ratio between the sodium and potassium ions in the medium might be responsible for the change in the type of polythionate accumulated by the organism. By the replacement of some of the potassium salts in the standard medium by the equivalent amounts of the sodium salts, media having ratios between the sodium and potassium ions of $2 \cdot 4: 1,5 \cdot 6: 1$, and $8 \cdot 7: 1$ were prepared. The type of polythionate accumulated by the organism growing in these media was compared with that accumulated during growth on the standard medium. A chromatogram was obtained from a culture in a medium having a ratio between the sodium and potassium ions of $5 \cdot 6: 1$, and was typical of the 
chromatograms obtained from the other two media which had high ratios between the sodium and potassium ions. The chromatogram showed accumulation of tetrathionate instead of trithionate, and also the component which ran in front of tetrathionate.

Further experiments were made to investigate the effect of decreasing the ratio of sodium ion to potassium ion below 0.93:1. Substitution of part of the sodium thiosulphate by the equivalent amount of the potassium salt produced a series of media having ratios of $0 \cdot 81: 1,0 \cdot 57: 1$, and $0 \cdot 45: 1$, between the sodium and potassium ions. The type of polythionate accumulated during the growth of Thiobacillus thioparus in these media was compared with that accumulated during growth in the standard medium. Typical chromatograms obtained from the cultures grown in the medium having a ratio of $\mathrm{Na}: \mathrm{K}$ of $0.57: 1$ showed the accumulation of trithionate and the component which ran in advance of the tetrathionate marker.

\section{DISCUSSION}

Evidence has been presented for the inclusion of polythionates in the pathway of thiosulphate oxidation by the thiobacilli and supports that obtained by Vishniac (1952) and Trudinger (1959) that the initial stages in thiosulphate oxidation by the thiobacilli are:

$$
\mathrm{S}_{2} \mathrm{O}_{3} \rightarrow \mathrm{S}_{4} \mathrm{O}_{6} \rightarrow \mathrm{S}_{3} \mathrm{O}_{6}
$$

Manometric experiments with suspensions of Thiobacillus thioparus and $T$. thiocyanoxidans showed both organisms to be capable of oxidising tetrathionate. The rate of oxidation of this substrate is similar to that shown by the second part of the thiosulphate oxidation curve (see Fig. $1 a$ and $b$ ). These results are similar to those obtained with $T$. thioparus by Vishniac (1952), except that the change in slope occurred at an oxygen absorption in excess of the $56 \mu$ l. observed by Vishniac. Baalsrud \& Baalsrud (1954) suggested that in the case of $T$. denitrificans such changes in the rate of thiosulphate oxidation were brought about by damage which the cells sustained when the $\mathrm{pH}$ value of the medium decreased during growth. Extending this view to $T$. thioparus and $T$. thiocyanoxidans it seems possible that the disparity between our results and those of Vishniac about the quantity of oxygen utilized before the change in rate of thiosulphate oxidation occurs was caused by this phenomenon.

Although we did not observe the presence of polythionates in the reaction vessels during manometric experiments, Thiobacillus thioparus was shown to accumulate considerable amounts of polythionate in the medium during growth on thiosulphate. Cultures grown in the standard thiosulphate medium were shown by chromatographic methods to accumulate trithionate and what may be pentathionate. The work of Vishniac \& Santer (1957) showed a requirement by suspensions of $T$. thioparus for phosphate or arsenate to allow complete oxidation of thiosulphate. Increasing the phosphate concentration of the growth medium to $\mathrm{M} / \mathbf{1 0}$ resulted in a considerable suppression of polythionate accumulation. Further experiments which involved altering the ratio between the sodium and potassium ions in the medium indicated that this ratio was also of importance in the oxidation of thiosulphate by growing cultures.

The absorption of potassium in yeast, Escherichia coli ' Bacterium lactis aerogenes' and some marine bacteria occurs only in the presence of a substance which can pro- 
duce energy; phosphate uptake by these species of organisms is stimulated by the presence of potassium, each $\mathrm{K}^{+}$ion being associated with the loss of a $\mathrm{H}^{+}$ion from the cell and each phosphate being associated with the gain of a $\mathrm{H}^{+}$ion by the cell (Rothstein, 1959). Comparable factors may well operate here, the lower concentrations of potassium in some of the media restricting the amount of phosphate entering the cell and thus preventing the further oxidation of tetrathionate.

Our initial experiments on the accumulation of polythionate in the medium were carried out with cultures of Thiobacillus thiocyanoxidans and $T$. thioparus; only very small amounts of polythionate were observed in the cultures of $T$. thiocyanoxidans.

From time to time there appear in the literature indications of more complex sulphur compounds as intermediates in the pathway of thiosulphate metabolism. Skarzynski \& Szczepkowski (1959) suggested that polythionates were not concerned, and that the sulphur passed through organic intermediates. Santer et al. (1960) also suggested the existence of an organic intermediate, and Trudinger (1959) showed the incorporation of radioactive sulphur into an unknown compound after its incorporation into tetrathionate and trithionate. There seems little doubt that polythionates are concerned in thiosulphate metabolism, and perhaps the suggested organic intermediates are concerned in the unknown steps which convert trithionate to sulphate.

One of the authors (G. L. J.) wishes to thank the Gas Council and the North Eastern Gas Board for financial assistance which made this work possible.

\section{REFERENCES}

Banlsnud, K. \& BaAlsrud, K. S. (1954). Studies on Thiobacillus denitrificans. Arch. Mikrobiol. 20, 34.

Nathansohn, (1902). Über eine neue Gruppe von Schwefelbakterien und ihren Stoffwechsel. Mitt. zool. Sta. Neapel. 15, 655.

PArker, C. D. \& Prisk, J. (1953). Oxidation of inorganic compounds of sulphur by various sulphur bacteria. J. gen. Microbiol. 8, 344.

Pollard, F. H., McOmie, J. F. W. \& Jones, D. J. (1955). The analysis of inorganic compounds by paper chromatography. Part VIII. The separation of the thionic acids by a new paper chromatographic technique. J. chem. Soc. p. 4337.

PratT, D. B. (1958). Detection of polythionate in cultures of Thiobacilli by means of the the Folin-Ciocalteu Reagent. Nature, Lond. 181, 1075.

Rothstein, A. (1959). Role of the cell membrane in the metabolism of inorganic electrolytes by microorganisms. Bact. Rev. 23, 175.

Santer, M., Marqulies, M., Kilnman, N. \& Kaback, R. (1960). Role of inorganic phosphate in thiosulphate metabolism by Thiobacillus thioparus. J. Bact. 79, 313.

SkARzYNSKI, B. \& Szczepkowski, T. W. (1959). Oxidation of thiosulphate by Thiobacillus thioparus. Nature, Lond. 183, 1413.

Stamm, H., Goehring, M. \& Feldmann, U. (1942). Zur Kenntnis der Polythionsaure und ihren Bildung. Neue verfahren zur Darstellung von Kaliumtrithionate und von Kaliumtetrathionate. Z. anorg. Chem. 250, 226.

STARKEY, R. L. (1934). The production of polythionates from thiosulphate by microorganisms. J. Bact. 28, 387.

Starkey, R. L. (1935). Products of the oxidation of thiosulphate by bacteria in mineral media. J. gen. Physiol. 18, 325.

Trudinger, P. A. (1959). The initial products of thiosulphate oxidation by Thiobacillus $\mathbf{x}$. Biochem. biophys. Acta, 31, 270.

Vishniac, W. (1952). The metabolism of Thiobacillus thioparus. I. The oxidation of thiosulphate. J. Bact. 64, 363.

Vishniac, W. \& Santer, M. (1957). The Thiobacilli. Bact. Rev. 21, 195. 